\title{
Cdc2 tyrosine phosphorylation is required for the DNA damage checkpoint in fission yeast
}

\author{
Nicholas Rhind, Beth Furnari, and Paul Russell ${ }^{1}$ \\ Departments of Molecular Biology and Cell Biology, The Scripps Research Institute, La Jolla, California 92037 USA
}

\begin{abstract}
A common cellular response to DNA damage is cell cycle arrest. This checkpoint control has been the subject of intensive genetic investigation, but the biochemical mechanism that prevents mitosis following DNA damage is unknown. In Schizosaccharomyces pombe, as well as vertebrates, the timing of mitosis under normal circumstances is determined by the balance of kinases and phosphatases that regulate inhibitory phosphorylation of Cdc2. In S. pombe, the phosphorylation occurs on tyrosine-15. This method of mitotic control is also used in $S$. pombe to couple mitosis with completion of DNA replication, but the role of Cdc2 tyrosine phosphorylation in the Chk1 kinase-mediated DNA damage checkpoint has remained uncertain. We show that, in contrast to recent speculation, the $G_{2}$ DNA damage checkpoint arrest in $S$. pombe depends on the inhibitory tyrosine phosphorylation of Cdc2 carried out by the Wee1 and Mik1 kinases. Furthermore, the rate of $\mathrm{Cdc2}$ tyrosine dephosphorylation is reduced by irradiation. This result implicates regulation of Cdc2 tyrosine dephosphorylation, mainly carried out by the Cdc25 tyrosine phosphatase, as an important part of the mechanism by which the DNA damage checkpoint induces Cdc2 inhibition and $\mathbf{G}_{\mathbf{2}}$ arrest.
\end{abstract}

[Key Words: Schizosaccharomyces pombe; mitotic control; DNA damage checkpoint; Cdc2; Tyrosine phosphorylation; Radiation]

Received November 13, 1996; revised version accepted January 14, 1997.

Cell cycle arrest in response to DNA damage is an important mechanism used to maintain genome integrity (Weinert and Hartwell 1988; Hartwell and Kastan 1994). In most cases, DNA damage leads to cell cycle arrest until the damage can be repaired or, in metazoan cells, programmed cell death can be activated. In the case of DNA damage during $G_{2}$, the cell cycle is arrested at the $\mathrm{G}_{2}-\mathrm{M}$ transition point. For a normal mammalian or fission yeast cell cycle, the timing of the $G_{2}-M$ transition is controlled by the inhibitory phosphorylation of $\mathrm{Cdc} 2$ (Russell and Nurse 1986, 1987; Gould and Nurse 1989; Krek and Nigg 1991; Norbury et al. 1991; McGowan and Russell 1993). In Schizosaccharomyces pombe, this phosphorylation occurs on tyrosine-15, whereas in mammalian cells the phosphorylation of both tyrosine-15 and threonine-14 play important roles in mitotic control. The tyrosine phosphorylation of $\mathrm{Cdc} 2$ is regulated by the balance of the activities of the tyrosine-15 kinases, encoded in S. pombe by wee $1^{+}$and $m i k 1^{+}$(Russell and Nurse 1987; Featherstone and Russell 1991; Lundgren et al. 1991; Parker et al. 1992; Lee et al. 1994), and phosphatases, the major one being encoded by $c d c 25^{+}$(Russell and Nurse 1986; Millar et al. 1991). During $G_{2}$ in $S$. pombe, $\mathrm{Cdc} 2$ is bound to cyclin B and is phosphorylated

${ }^{1}$ Corresponding author.

E-mail prussell@scripps.edu; FAX (619) 784-2265. on threonine-167, but its activity remains low as a result of the phosphorylation of tyrosine-15, the only tyrosine residue of $\mathrm{Cdc} 2$ that is phosphorylated, and mitosis is prevented (Gould and Nurse 1989; Gould et al. 1991). At the $G_{2}-M$ transition, $C d c 2$ is tyrosine dephosphorylated and activated, and mitosis ensues.

The $\mathrm{G}_{2}$ DNA damage checkpoint has been investigated in a number of systems, but the mechanism of the arrest has remained unclear. In Saccharomyces cerevisae, it has been shown that the checkpoint is independent of CDC28 tyrosine phosphorylation (Sorger and Murray 1992). This may reflect the fact that, in $S$. cerevisiae, CDC28 tyrosine phosphorylation does not play a central role in mitotic control (Amon et al. 1992; Sorger and Murray 1992). In mammalian cells there have been several studies that show a correlation between activation of the $G_{2}$ DNA damage checkpoint, tyrosine phosphorylation of $\mathrm{Cdc} 2$, and a failure to activate $\mathrm{Cdc} 25 \mathrm{C}$ (O'Connor et al. 1994; Herzinger et al. 1995). However, it was not possible to determine whether these observations were the cause or effect of the checkpoint. Recently it has been shown that expression of an unphosphorylatable mutant of Cdc2, Cdc2-AF, in HeLa cells compromises the $\mathrm{G}_{2}$ DNA damage checkpoint. Cdc2-AF cells irradiated during $S$ phase fail to exhibit a normal $G_{2}$ delay (Jin et al. 1996). Cdc2-AF expression also prevents $\mathrm{Cdc} 2$ activation from being blocked by radiation during 
$\mathrm{G}_{2}$ (A. Blasina and C. McGowan, pers. comm.). These findings suggest that maintenance of the inhibitory phosphorylation of Cdc2 is important for the $G_{2}$ DNA damage checkpoint in mammalian cells, although there may also be other mechanisms that contribute to the checkpoint.

In $S$. pombe, a large number of genes involved in both the $G_{2}$ DNA damage checkpoint and the S-phase replication checkpoint have been identified. Many of these genes, including rad1, rad3, rad9, and rad17, are required for both the DNA damage checkpoint and the replication checkpoint that prevents mitosis in the presence of unreplicated DNA (al-Khodairy and Carr 1992). It is thought that these genes, which are collectively referred to as the checkpoint rad genes, are involved in a signal transduction pathway that results in the inhibition of mitosis. For the replication checkpoint, it is believed that mitosis is inhibited by maintaining Cdc2 in its tyrosine phosphorylated $\mathrm{G}_{2}$ form (Enoch and Nurse 1990; Sorger and Murray 1992). In contrast, it has been proposed that the DNA damage checkpoint acts by a different mechanism, dependent on the protein kinase Chk 1 , that does not require $\mathrm{Cdc} 2$ tyrosine phosphorylation (Sheldrick and Carr 1993; Carr 1995). chk1 is a checkpoint gene that acts downstream of the checkpoint rad genes and appears to be required only for the DNA damage checkpoint and not the replication checkpoint (Walworth et al. 1993; al-Khodairy et al. 1994; Walworth and Bernards 1996). It is thus conceivable that the checkpoint pathway diverges after the checkpoint rad genes, with the replication checkpoint signal leading to inhibition of mitosis by tyrosine phosphorylation of $\mathrm{Cdc} 2$, whereas the DNA damage signal is transduced by Chk1 to inhibit mitosis through a Cdc2 tyrosine phosphorylation-independent mechanism. We undertook to test this idea and found, on the contrary, that the Chkl dependent DNA damage checkpoint acts to prevent mitosis via inhibitory tyrosine phosphorylation of $\mathrm{Cdc} 2$.

\section{Results}

\section{Tyrosine phosphorylation of $\mathrm{Cdc} 2$ is maintained} during a radiation-induced $G_{2}$ cell cycle arrest

Initially, we examined the tyrosine phosphorylation state of Cdc2 during a $\gamma$-radiation-induced cell cycle arrest. Centrifugal elutriation was used to generate a synchronous population of wild-type cells. These cells were irradiated early in $\mathrm{G}_{2}$ with $100 \mathrm{~Gy}$, enough to delay mitosis for -1 hr relative to an unirradiated sample of the culture (Fig. 1A). Complexes between $\mathrm{Cdc} 2$ and $\mathrm{Cdc13}$, which constitute the $S$. pombe mitotic CDK/cyclin B pair, were isolated by immunoprecipitation with $\alpha$-Cdc13 antiserum. The immunoprecipitated $\mathrm{Cdc} 2$ was assayed for tyrosine phosphorylation by immunoblotting with monoclonal $\alpha$-phosphotyrosine antibodies. As an internal control, the blot was reprobed with monoclonal antibodies against the PSTAIR motif of Cdc2. During the period of the cell cycle arrest induced by $\gamma$-radiation, $\mathrm{Cdc} 2$ remained in its tyrosine phosphorylated interphase
A
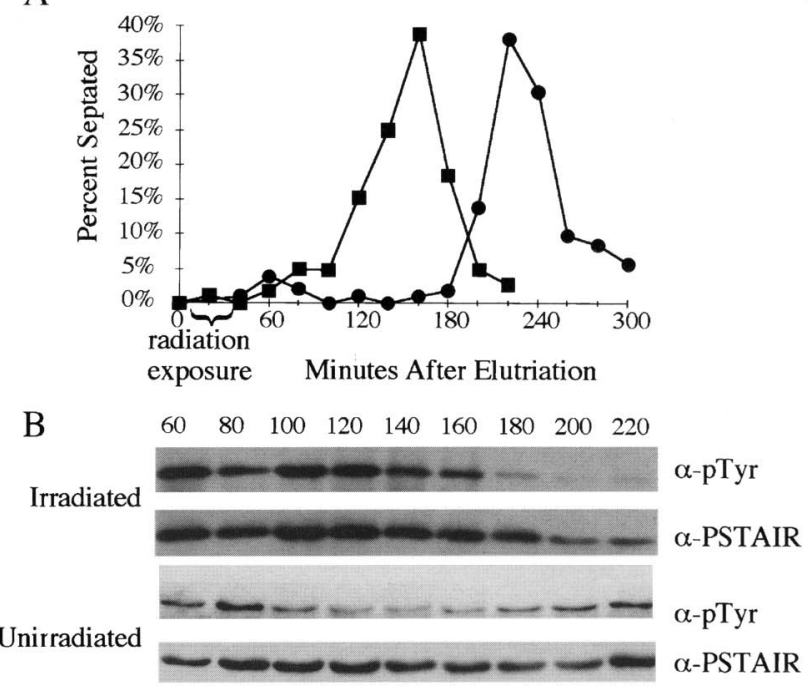

Figure 1. A radiation-induced $\mathrm{G}_{2}$ cell cycle delay correlates with the continued tyrosine phosphorylation of Cdc2. (A) Centrifugal elutriation was used to generate a synchronous population of wild-type cells (PR109) in early $\mathrm{G}_{2}$ phase. Half of the culture of was irradiated with $100 \mathrm{~Gy}$ of $\gamma$-radiation. The subsequent cell cycle progression of the irradiated $(0)$ and unirradiated ( $\mathbf{\square}$ ) cultures was monitored by counting the percent of cells undergoing septation. $(B) \mathrm{Cdc} 2$ coimmunoprecipitated from samples of the same cultures with $\alpha$-Cdc13 antibodies was analyzed by Western blotting with an anti-phosphotyrosine antibody. The blots were reprobed with an anti-PSTAIR antibody to visualize the total amount of Cdc2 present in the immunoprecipitates.

form, even though the cells continued to grow past the size at which Cdc2 is normally dephosphorylated (Fig. 1B). Not until $180 \mathrm{~min}$, as irradiated cells began to enter mitosis, did Cdc2 become tyrosine dephosphorylated. In addition, the $\alpha$-PSTAIR signal decreased shortly after the dephosphorylation of $\mathrm{Cdc} 2$, as a result of the destruction of Cdc13 as cells exit mitosis (Moreno et al. 1989). The fact that the amount of coprecipitated Cdc2 does not decrease during the arrest shows that the checkpoint does not operate by destroying $\mathrm{Cdc} 13$ or by otherwise disrupting the $\mathrm{Cdc} 2 / \mathrm{Cdc} 13$ complex. We have repeated this experiment to examine the tyrosine phosphorylation of total $\mathrm{Cdc} 2$ instead of $\mathrm{Cdc} 13$ bound $\mathrm{Cdc} 2$ and found identical results (Fig. 5C, below; data not shown). Thus in $S$. pombe, $\mathrm{Cdc} 2$ is maintained in its tyrosine phosphorylated form during a radiation-induced cell cycle arrest.

Cdc2 tyrosine-15 phosphorylation is required for the $G_{2} D N A$ damage checkpoint

To determine whether the observed correlation between radiation-induced cell cycle arrest and $\mathrm{Cdc} 2$ tyrosine phosphorylation reflects an important role for Cdc2 phosphorylation in the checkpoint, we examined the radiation response of cells expressing an unphosphorylat- 
able form of Cdc2. Cdc2-Y15F has a phenylalanine in place of tyrosine-15, and is therefore not subject to regulation by tyrosine phosphorylation (Gould and Nurse 1989). Centrifugal elutriation was used to produce a synchronous $\mathrm{G}_{2}$ culture of a $c d c 2-Y 15 F$ strain, carrying this dominant $c d c 2-Y 15 F$ allele integrated in a $c d c 2^{+}$background. One-half of this culture was exposed to $\gamma$-radiation for the duration of the experiment. The irradiated and unirradiated cultures proceeded through mitosis with indistinguishable kinetics (Fig. 2). Thus, in the absence of tyrosine phosphorylation of Cdc2, the DNA damage checkpoint is abolished.

\section{Overproduction of Cdc25 overrides the $G_{2} D N A$ damage checkpoint}

As an independent confirmation of the importance of Cdc2 tyrosine-15 phosphorylation in the DNA damage checkpoint, we examined the effect of overexpressing $\mathrm{Cdc} 25$, the major Cdc2 tyrosine-15 phosphatase, on the radiation response. If tyrosine phosphorylation of $\mathrm{Cdc} 2$ is necessary to prevent mitosis in response to DNA damage, then dephosphorylating $\mathrm{Cdc} 2$ by overexpressing Cdc25 should abrogate this radiation checkpoint, as it does the replication checkpoint (Enoch and Nurse 1990). To test this prediction, we used a strain carrying an integrated copy of $c d c 25^{+}$driven by the strong thiamine repressible $n m t 1$ promoter (Maundrell 1990) in a $c d c 25^{+}$ background. The nmt1-cdc2 $5^{+}$cells were grown in media lacking thiamine to induce overexpression of Cdc25, and then irradiated for $3 \mathrm{hr}$ at $200 \mathrm{~Gy} / \mathrm{hr}$. Cdc25 overexpression overrides the DNA damage checkpoint, preventing cells from arresting in response to radiation (cf. Fig. 3A, left panels). The control nmt1-cdc25 cells not

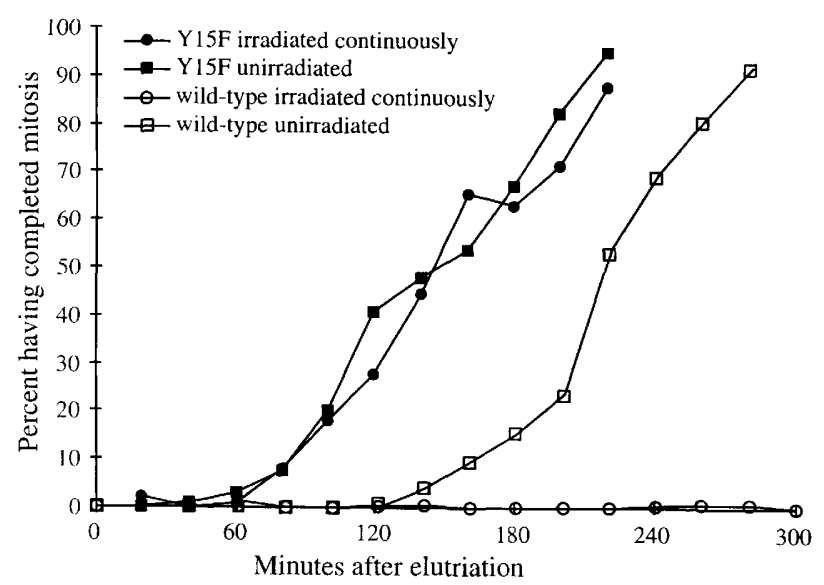

Figure 2. Cdc2 tyrosine phosphorylation is required for a radiation-induced cell cycle arrest. Synchronous $\mathrm{G}_{2}$ cultures of cdc2-Y15F (PR714) (solid symbols) or wild-type (PR109) (open symbols) cells were prepared by centrifugal elutriation. The cultures were then split and half was exposed to $\gamma$-radiation (circles). Every $20 \mathrm{~min}$ the cultures were examined microscopically to determine what percent of the cells had gone through mitosis. Note that the $c d c 2-Y 15 F$ cells are wee and therefore underwent mitosis early relative to the wild-type cells.
A
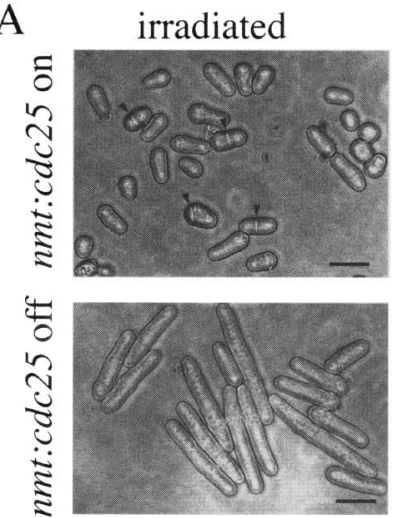

$\mathrm{B}$
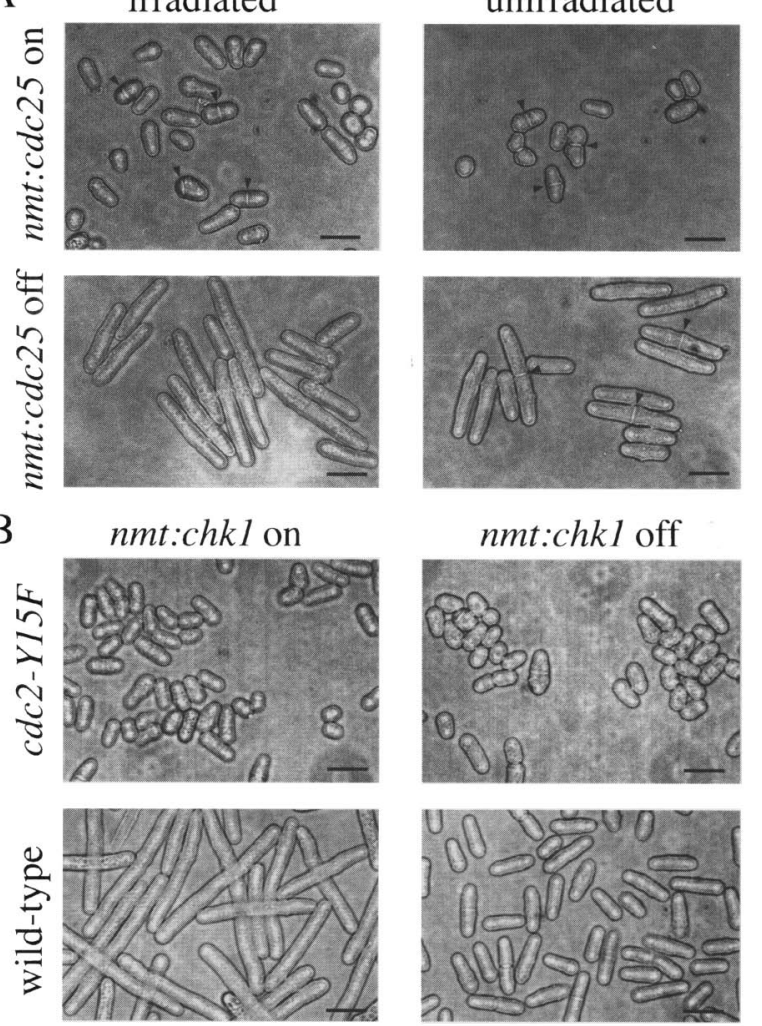

$n m t: \operatorname{chk} l$ off
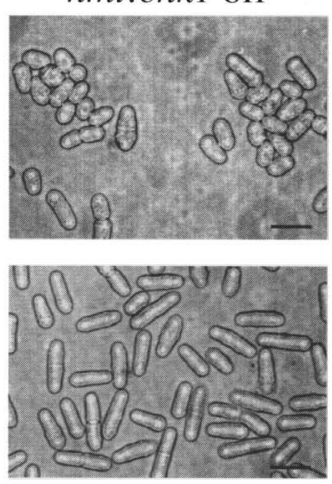

Figure 3. $(A)$ Cells overexpressing Cdc 25 from the thiamine repressible $n m t 1$ promoter do not arrest in response $\gamma$-radiation. The cells (GL198) in the left panels were exposed to $\gamma$-radiation for $3 \mathrm{hr}$; those in the right panels were not. Cells in the top panels were grown for $23 \mathrm{hr}$ in media lacking thiamine and therefore express high levels of $\mathrm{Cdc} 25$; those in the bottom panels were grown with thiamine and so do not overexpress Cdc25. Arrowheads show septa, which indicate cells that have just finished mitosis. The asymmetric septum in the top right panel is a common result of premature mitosis and is occasionally seen in cells overexpressing $\mathrm{Cdc} 25$. (B) Chk1 overexpression arrest requires tyrosine- 15 phosphorylation of Cdc2. $c d c 2-$ Y15F (NR1775) or wild-type (BF1758) cells carrying an integrated nmt1-GST-chk $1^{+}$fusion were grown in the absence (left panels) or presence (right panels), of thiamine for $18 \mathrm{hr}$. Similar results were obtained using an unintegrated $n m t 1-\operatorname{chk} 1 \mathrm{fu}-$ sion without the GST tag (data not shown). $(A, B)$ Bar, $\sim 10 \mu \mathrm{m}$.

overexpressing Cdc25 arrested within $1 \mathrm{hr}$ of of the initiation of irradiation, whereas the $n m t 1-c d c 25^{+}$cells overexpressing Cdc 25 continued to divide for $>3 \mathrm{hr}$.

\section{cdc2-Y15F cells are insensitive to Chk1} overproduction

The Chkl kinase is required for the DNA damage checkpoint and is believed to be a downstream member of the checkpoint signal transduction pathway (Walworth and Bernards 1996). Overexpression of Chk1 from the $n m t 1$ promoter causes cells to arrest in $\mathrm{G}_{2}$ and elongate (Ford et al. 1994; data not shown). It is thought that this phe- 
notype is attributable to inappropriate activation of the DNA damage checkpoint. To further investigate the mechanism of the Chk1-mediated checkpoint, we tested the requirement of $\mathrm{Cdc} 2$ tyrosine phosphorylation for the Chk1 overexpression arrest. Chk1 was overexpressed as a GST fusion protein from the nmt1 promoter in both wild-type and $c d c 2-Y 15 F$ cells. Whereas the wild-type cells overexpressing Chk1 show a $c d c$-arrest phenotype, this phenotype is suppressed by $c d c 2-Y 15 F$ (Fig. 3B, cf. left panels). These results demonstrate that the Chkl overexpression phenotype requires $\mathrm{Cdc} 2$ tyrosine phosphorylation.

\section{Decrease in the rate of Cdc2 tyrosine} dephosphorylation in response to DNA damage

The maintenance of $\mathrm{Cdc} 2$ tyrosine phosphorylation during a DNA damage-induced arrest could be a result of either an increase in the rate of phosphorylation, a decrease in the rate of dephosphorylation, or both. We investigated these possibilities by removing the Cdc2 tyrosine kinases during radiation-induced arrest. Weel and Mikl are the two tyrosine kinases responsible for phosphorylating Cdc2 on tyrosine-15, with Weel having the major activity (Lundgren et al. 1991). wee1-50 mik1s double mutant cells, which have a temperature-sensitive wee1 allele and lack a mik1 gene, grow normally at the permissive temperature of $25^{\circ} \mathrm{C}$, but when shifted to the restrictive temperature of $35^{\circ} \mathrm{C}$, at which temperature Weel-50 displays no measurable activity, they rapidly lose detectable Cdc2 tyrosine phosphorylation and enter mitosis regardless of size (Lundgren et al. 1991). We arrested a synchronous $G_{2}$ population of wee1-50 mik1s cells with $\gamma$-radiation at $25^{\circ} \mathrm{C}$ and then shifted half of the culture to $35^{\circ} \mathrm{C}$, maintaining both cultures in the continued presence of radiation. Under these conditions, the cells at $25^{\circ} \mathrm{C}$ stayed arrested, whereas the cells at $35^{\circ} \mathrm{C}$ rapidly divided (Fig. 4). This result confirms the cdc2Y15F results by demonstrating that the activities of Weel and Mik1, and thus presumably the tyrosine-15 phosphorylation of $\mathrm{Cdc} 2$, are required to maintain a cell cycle arrest in response to ionizing radiation. However, the irradiated wee1-50 mik1s cells shifted to $35^{\circ} \mathrm{C}$ did show a mitotic delay of $\sim 40 \mathrm{~min}$, relative to the unirradiated control (Fig. 4). Thus, even in the absence of Cdc2 tyrosine-15 kinase activity, the cell cycle can be delayed in response to DNA damage. This result shows that regulation of the Weel and Mik1 kinases is not absolutely required for a transient checkpoint delay. Because, as we have shown, tyrosine phosphorylation of Cdc2 is absolutely required for the DNA damage checkpoint, the ability of cells to delay mitosis in the absence of the $\mathrm{Cdc} 2$ tyrosine kinases implicates regulation of Cdc2 tyrosine dephosphorylation in the checkpoint mechanism.

To confirm that Cdc2 tyrosine dephosphorylation is regulated by the DNA damage checkpoint, we directly monitored the level of Cdc2 tyrosine phosphorylation in irradiated cells after the elimination of Wee1 and Mik1. wee1-50 mik1s cells were synchronized, irradiated, and analyzed as the wild-type cells in Figure 1, except that

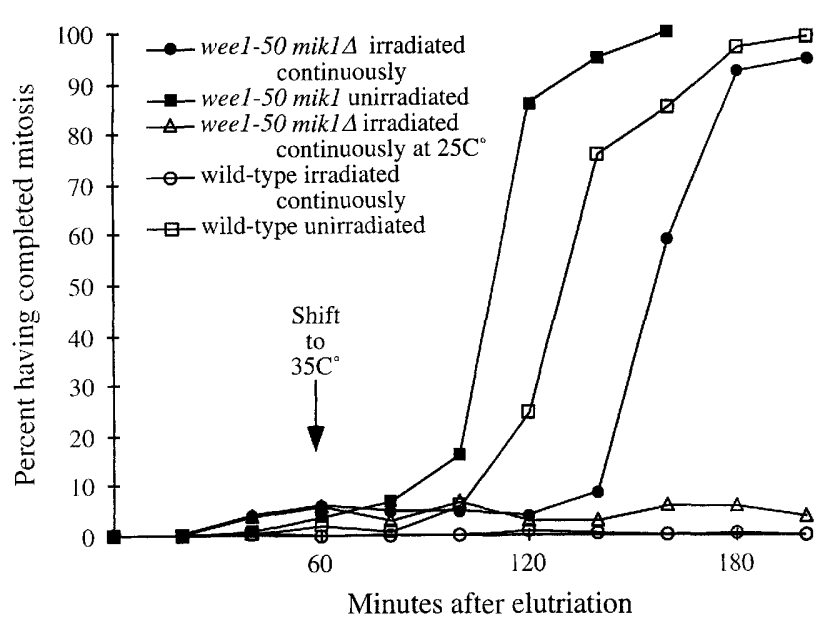

Figure 4. The Cdc2 tyrosine-15 kinases, Wee1 and Mik1, are required for a radiation-induced $\mathrm{G}_{2}$ cell cycle arrest. Synchronous $\mathrm{G}_{2}$ cultures of wee1-50 mik1s (PR754) or wild-type (PR109) cells were arrested by exposure to $\gamma$-radiation at the permissive temperature of $25^{\circ} \mathrm{C}$ for $60 \mathrm{~min}$. Then half of both the irradiated and unirradiated cultures were shifted to the restrictive temperature of $35^{\circ} \mathrm{C}$ and radiation exposure was continued. Every $20 \mathrm{~min}$ the cultures were examined microscopically to determine what percent of the cells had gone through mitosis. For clarity, the data for the unirradiated wee1-50 mik $1 \Delta$ culture at $25^{\circ} \mathrm{C}$ and both wild-type cultures at $25^{\circ} \mathrm{C}$ are not shown.

after exposure to radiation half of the culture was shifted to $35^{\circ} \mathrm{C}$. As in the continuous exposure experiment (Fig. 4), the wee1-50 mik1 $1 \Delta$ cells shifted to $35^{\circ} \mathrm{C}$ showed a radiation induced delay of mitosis (Fig. 5A). However, they also showed a corresponding radiation-induced delay in dephosphorylation of Cdc2 (Fig. 5B). Thus, radiation exposure causes $\mathrm{Cdc} 2$ to be maintained in its inactive tyrosine phosphorylated state even in the absence of active Cdc2 tyrosine kinases.

In Figure $5 B$, the $\alpha$-PSTAIR signal decreased shortly after the dephosphorylation of Cdc2, as a result of the destruction of Cdc13 as cells exit mitosis (Moreno et al. 1989|. To show more clearly that the observed decrease in the $\alpha$-phosphotyrosine signal is attributable to dephosphorylation of $\mathrm{Cdc} 2$ and is independent of the decrease in the amount of immunoprecipitated $\mathrm{Cdc} 2$, we repeated the above experiment, but isolated total Cdc2 instead of that bound to Cdc13. As above, Cdc2 stayed tyrosine phosphorylated at its interphase level during the radiation arrest. It was then rapidly dephosphorylated as the cells began to enter mitosis (Fig. 5C).

\section{Discussion}

The role of Cdc2 tyrosine-15 phosphorylation in the $G_{2} D N A$ damage checkpoint

We have shown that the $\mathrm{G}_{2}$ DNA damage checkpoint in $S$. pombe is completely dependent upon the inhibitory phosphorylation of Cdc2 on tyrosine-15. This is demonstrated by three independent methods of compromising 


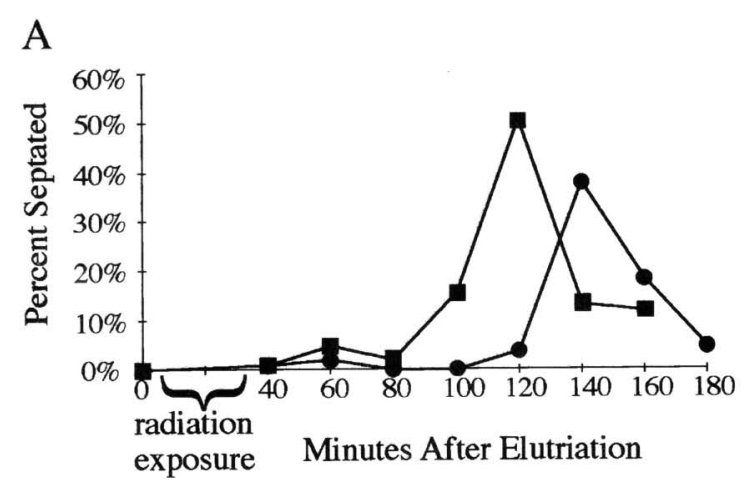

B $\begin{array}{llllll}40 & 60 & 80 & 100 & 120 & 140\end{array}$

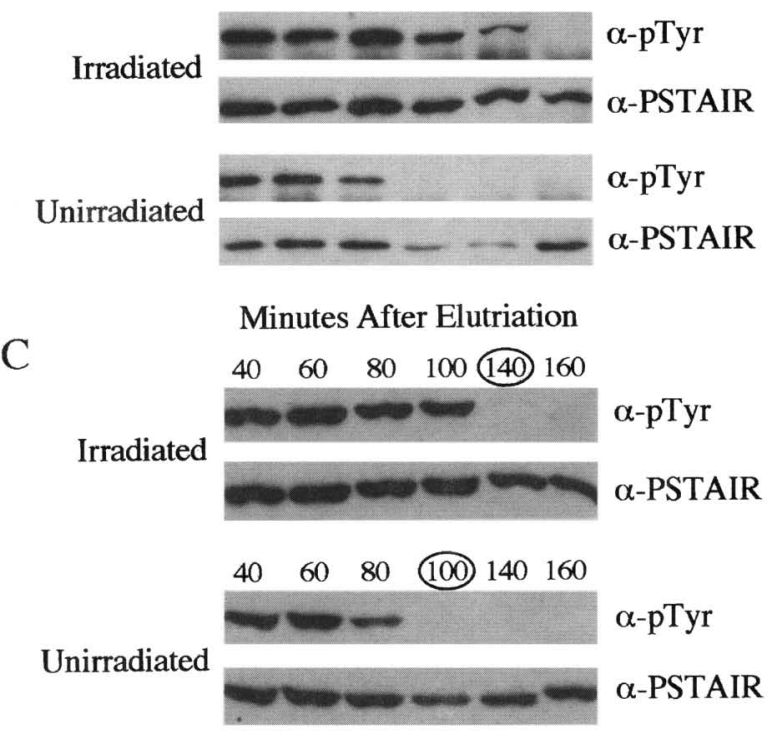

Figure 5. A radiation-induced cell cycle delay correlates with the continued tyrosine phosphorylation of $\mathrm{Cdc} 2$ even in the absence of the Cdc2 tyrosine kinases. (A) Half of a synchronous culture of wee $1-50$ mik1s cells (PR754) in early $\mathrm{G}_{2}$ was irradiated ( $)$ with $100 \mathrm{~Gy}$ of $\gamma$-radiation; ( $)$ unirradiated cells. After $40 \mathrm{~min}$ the cultures were shifted to $35^{\circ} \mathrm{C}$ to inactivate Weel. Subsequent cell cycle progression was monitored by counting the percent of cells undergoing septation. $(B) \mathrm{Cdc} 2$ coimmunoprecipitated from samples of the same cultures with $\alpha$-Cdc13 antibodies was analyzed as in Fig. 1. All samples were analyzed on the same gel and data shown is from the same exposure. The background band at the bottom of the $\alpha$-phosphotyrosine blots is a result of immunoglobulin light chain. $(C)$ The experiment was repeated, but total $\mathrm{Cdc} 2$ was isolated by binding to Suclcoated beads (Brizuela et al. 1987). The time at which half the cells had septated is circled. The irradiated 120 -min sample was lost during preparation.

the ability of cells to phosphorylate Cdc2. First, a substitution of a phenylalanine for tyrosine- 15 in Cdc2, so that the protein can no longer be tyrosine phosphorylated, completely abolishes the checkpoint (Fig. 2). Second, overexpression of $\mathrm{Cdc} 25$, the major Cdc2 tyrosine15 phosphatase, likewise drives cells through the checkpoint (Fig. 3A). Finally, inactivation of the Weel and Mikl, the two Cdc2 tyrosine kinases, after the check- point is established causes the checkpoint to fail and cells to re-enter the cell cycle (Fig. 4). These results are consistent with the simple model that the $\mathrm{G}_{2}$ DNA damage checkpoint operates by maintaining Cdc2 in its tyrosine-phosphorylated $\mathrm{G}_{2}$ form while the DNA damage signal persists, thus preventing mitosis. We cannot exclude more complicated models that postulate the existence of some other form of negative regulation of $\mathrm{Cdc} 2$ that is effective only in concert with tyrosine phosphorylation of Cdc2. However, given the fact that tyrosine phosphorylation of $\mathrm{Cdc} 2$ is both necessary and sufficient to arrest cells in $\mathrm{G}_{2}$, such models are not required (Russell and Nurse 1987; Aligue et al. 1994; this study).

There has been speculation that the $S$. pombe $\mathrm{G}_{2}$ DNA damage checkpoint may be independent of $\mathrm{Cdc} 2$ tyrosine-15 phosphorylation (Sheldrick and Carr 1993; Carr 1995). This hypothesis is based largely on the observation that wee1-50 mik1 $1 \Delta$ cells show a cell cycle delay in response to radiation at the restrictive temperature. The fact that the kinases are not required for a short cell cycle delay was interpreted to demonstrate that tyrosine phosphorylation of Cdc2 was not required for the delay. As we have shown in Figures 4 and 5, wee1-50 mik1s cells do show a transient cell cycle delay in response to radiation at the restrictive temperature. However, the tyrosine-15 kinase activity of Weel and Mik1 is only half of the equilibrium that maintains the phosphorylation of Cdc2. Even in the absence of these kinases, the DNA damage checkpoint reduces the rate of tyrosine dephosphorylation of $\mathrm{Cdc} 2$, maintaining $\mathrm{Cdc} 2$ in its tyrosine phosphorylated state and leading to a transient cell cycle delay (Fig. 5B). These results explain the previous observations with the wee1-50 mik1s strain (Sheldrick and Carr 1993) and reconcile them with the absolute requirement of Cdc2 tyrosine- 15 phosphorylation in the $G_{2}$ DNA damage checkpoint.

The role of the Cdc2 tyrosine phosphatase and kinases in the $G_{2} D N A$ damage checkpoint

The central role for Cdc2 tyrosine-15 phosphorylation in the $G_{2}$ DNA damage checkpoint raises the question of how this phosphorylation is regulated. Although we cannot directly answer this question, our results suggest that rate of tyrosine dephosphorylation of $\mathrm{Cdc} 2$ plays an important role in the mechanism of the checkpoint. When Weel and Mik1, the kinases that phosphorylate Cdc2 on tyrosine-15, are inactivated, there is still a radiation-induced delay of Cdc2 tyrosine dephosphorylation (Fig. 5B). This delay can be attributed only to a change in the rate of dephosphorylation of Cdc2. This delayed dephosphorylation of Cdc2 is presumably a result of a reduction in the activity of Cdc25, the major Cdc2 tyrosine-15 phosphatase in fission yeast (Millar et al. 1991, 1992). The reduction of the Cdc25 activity could be through direct down-regulation of enzyme-specific activity or abundance, or through changes in the accessibility of Cdc2. The mitotic induction process is 
thought to involve a positive feedback loop in which $\mathrm{Cdc} 2$ catalyzes directly or indirectly the activation of Cdc25 via phosphorylation (Dunphy 1994; Kumagai and Dunphy 1996). In $S$. pombe, the activations of Cdc2 and Cdc25 that occur at the $G_{2}-M$ transition are mutually dependent, observations consistent with a Cdc2-Cdc25 positive feedback loop (Gould and Nurse 1989; Kovelman and Russell 1996). Therefore, one possible mechanism for the inhibition of Cdc2 tyrosine dephosphorylation is the interruption of this Cdc 25 activation loop.

Our findings do not exclude the possibility that the checkpoint mechanism also involves up-regulation of Weel and/or Mik1 following DNA damage. Because wee 1-50 mik1 1 cells are able to arrest at the permissive temperature, Mik1 alone cannot be required for the arrest. Likewise, wee $1 \Delta$ cells also exhibit a cell cycle arrest under the same conditions (data not shown), in agreement with previous results (Barbet and Carr 1993). Thus, Weel and Mikl provide redundant activities in the $\mathrm{G}_{2}$ DNA damage checkpoint. However, it remains to be seen whether Weel and Mikl simply serve in their regular $G_{2}$ role to phosphorylate $\mathrm{Cdc} 2$ or whether the activities of these kinases are up-regulated in response to DNA damage.

The role of $\mathrm{Cdc2}$ tyrosine phosphorylation in other species

In view of the high degree of conservation of mitotic controls among eukaryotic species, it is reasonable to speculate that the checkpoint mechanisms regulating mitosis would also be conserved (Nurse 1990; Dunphy 1994). This is, however, not the case for $S$. cerevisiae, where tyrosine phosphorylation of CDC28 does not play a major role in mitotic control or in the DNA damage checkpoint (Amon et al. 1992; Sorger and Murray 1992). The situation also seems to be more complicated in mammalian cells. It has not been possible to test directly whether Weel-like kinases are required for the DNA damage $\mathrm{G}_{2}$ checkpoint in mammals, although maintenance of $\mathrm{Cdc} 2$ tyrosine phosphorylation and a failure to activate $\mathrm{Cdc} 25 \mathrm{C}$ tyrosine phosphatase are correlated with $\mathrm{G}_{2}$ arrest induced by DNA damage $\left(\mathrm{O}^{\prime}\right.$ Connor et al. 1994; Herzinger et al. 1995). Furthermore, expression of the unphosphorylatable Cdc2-AF mutant in HeLa cells prevents $\mathrm{Cdc} 2$ activation from being blocked by the checkpoint and greatly reduces the $G_{2}$ delay in response to radiation (Jin et al. 1996; A. Blasina and C. McGowan, pers. comm.). This demonstrates that tyrosine phosphorylation of Cdc2 is a important part of the $G_{2}$ DNA damage checkpoint in mammals. However, Cdc2-AF expression does not abolish the checkpoint completely. Instead, cells go into a delayed or abnormal mitosis (Jin et al. 1996; A. Blasina and C. McGowan, pers. comm.). This may reflect the fact that mammalian cells appear to have multiple controls over the initiation of mitosis, one involving $\mathrm{Cdc} 2$ and another involving the NIMA protein kinase (Fry and Nigg 1995; Lu and Hunter 1995). Thus it is possible that tyrosine phosphorylation of $\mathrm{Cdc} 2$ is responsible for restraining $\mathrm{Cdc} 2$ activity in response to DNA damage and that another checkpoint mechanism regulates other mitotic controls. The obvious conclusion is that there is a correlation between the importance of Cdc2 tyrosine phosphorylation in normal mitotic control and its role in the $\mathrm{G}_{2}$ DNA damage checkpoint. This correlation implies that the $\mathrm{G}_{2}$ DNA damage checkpoint in various organisms relies on whatever mechanism controls the timing of normal mitoses. By feeding in upstream of the normal mitotic controls, the DNA damage checkpoint is able to utilize efficiently the regulator machinery that is already in place.

\section{Materials and methods}

General methods for studying fission yeast were performed as described (Moreno et al. 1991). Unless otherwise stated all strains (Table 1) were grown in yeast extract-glucose (YES) media at $25^{\circ} \mathrm{C}$. Synchronous cultures were prepared by centrifugal elutriation with a Beckman JE-5.0 elutriation rotor (Creanor and Mitchison 1979). Cells were irradiated with $\gamma$-radiation from a ${ }^{137} \mathrm{Cs}$ source at $3.3 \mathrm{~Gy} / \mathrm{min}$ at room temperature, which ranged from $23^{\circ} \mathrm{C}$ to $25^{\circ} \mathrm{C}$. For the wee1-50 mik1s temperature shift irradiation experiment, after $60 \mathrm{~min}$ of irradiation at room temperature, half of each of the irradiated and unirradiated cultures were shifted $35^{\circ} \mathrm{C}$. To continue radiation exposure at $35^{\circ} \mathrm{C}$, the $35^{\circ} \mathrm{C}$ irradiated culture was alternatively irradiated for $20 \mathrm{~min}$ and then incubated at $35^{\circ} \mathrm{C}$ for $20 \mathrm{~min}$. The temperature of the culture varied between $32^{\circ} \mathrm{C}$ and $35^{\circ} \mathrm{C}$. The $25^{\circ} \mathrm{C}$ irradiated culture was irradiated in the same manner and varied between $24^{\circ} \mathrm{C}$ and $25^{\circ} \mathrm{C}$. The number of cell having passed mitosis was determined by the number of cells having begun or finished septation divided by the total number of cells.

Table 1. S. pombe strains used in this study

\begin{tabular}{|c|c|c|}
\hline Strain & Genotype $^{a}$ & Reference \\
\hline PR109 & $h^{-}$ & laboratory stock \\
\hline PR714 & $h^{-} c d c 2^{+}: c d c 2-Y 15 F: L E U 2$ & K. Gould (unpubl.) \\
\hline GL198 & $h^{-} c d c 25^{+}: n m t 1-c d c 25: u r a 4^{+}$ & G. Lenaers and P. Russell (unpubl.) \\
\hline OM1603 & $h^{+}$ura4-294 & laboratory stock \\
\hline BF1758 & $h^{+}$ura4-294 leu1-32:nmt1-GST-chk1:leu1 ${ }^{+}$ & this study \\
\hline NR1757 & $\begin{array}{l}h^{-} \text {ura4-294 leu1-32:nmt1-GST-chk1:leu1 } 1^{+} \\
\text {cdc2 } 2^{+}: c d c 2-Y 15 F: L E U 2\end{array}$ & this study \\
\hline PR754 & $h^{-}$wee1-50 mik1::ura4 ${ }^{+}$ & laboratory stock \\
\hline
\end{tabular}

${ }^{a}$ All strains are leu1-32 ura4-D18 unless otherwise noted. 
For $n m t 1$ expression experiments, cells were grown in Edinburgh minimal media 2 (EMM2), supplemented with leucine, uracil, adenine, and histidine, with or without $5 \mu \mathrm{g} / \mathrm{ml}$ thiamine. For the Cdc25 overexpression experiments, cells were grown for $20 \mathrm{hr}$ without thiamine and then irradiated for $3 \mathrm{hr}$ in the same media. For the Chk1 overexpression experiments, cells were grown without thiamine for $18 \mathrm{hr}$. In both cases, cells were photographed using phase contrast optics.

\section{Immunoprecipitations and Western blots}

For each sample, $10 \mathrm{OD}_{600}$ units of cells were harvested by centrifugation, washed once in ice-cold stop buffer $1150 \mathrm{~mm}$ $\mathrm{NaCl}, 50 \mathrm{~mm} \mathrm{NaF}, 10 \mathrm{~mm}$ EDTA, $1 \mathrm{mM} \mathrm{NaN}_{3}$ l, and frozen as cell pellets at $-70^{\circ} \mathrm{C}$. All steps in the immunoprecipitations were done at $4^{\circ} \mathrm{C}$, using standard procedures (Harlow and Lane 1988). Cells were thawed in $200 \mu \mathrm{l}$ of lysis buffer ( $150 \mathrm{~mm} \mathrm{NaCl}$, $50 \mathrm{~mm}$ Tris at pH 8.0, $50 \mathrm{~mm} \mathrm{NaF}, 5 \mathrm{~mm}$ EDTA, $1 \mathrm{~mm} \mathrm{NaVnO}_{4}$, $1 \mathrm{mM}$ PMSF, $10 \%$ glycerol, $1 \% \mathrm{NP}-40$, and $5 \mu \mathrm{g} / \mathrm{ml}$ each of aprotinin, leupeptin, and pepstatin), broken by vortexing with glass beads, and centrifuged to prepare a cleared cell extract. The protein concentrations of the supernatants were measured at $280 \mathrm{~nm}$ and normalized with lysis buffer. Cdc13 was immunoprecipitated using the polyclonal rabbit serum E7 bound to protein A-Sepharose. The Sepharose beads were washed 3 times with Lysis buffer and then boiled in SDS-PAGE sample loading buffer. Samples were electrophoresed on a $6 \%-12 \%$ polyacrylamide gradient gel and transferred to Immobilon (Millipore) with a semi-dry blotting apparatus. The blots were probed with a mouse monoclonal antibody against phosphotyrosine (Upstate Biotech), then stripped and reprobed with a mouse monoclonal antibody against the PSTAIR peptide. In both cases, the primary antibody was detected using an HPR-conjugated antimouse IgG antibodies (Promega) and Luminol reagents (Pierce). For the Sucl precipitations, Sepharose-coupled Sucl was substituted for protein A-Sepharose-bound $\alpha$-Cdc13 antibodies (Brizuela et al. 1987).

\section{Construction of the nmt1-GST-chk1 fusion}

The nmt1-GST-chk1 fusion (pBF147) was constructed by inserting the coding region of GST flanked with NdeI sites into the NdeI site of the pRepl based nmt1-chk1 expression plasmid (pBF146) (Maundrell 1993). The activity of the GST-Chk1 fusion was confirmed by overexpression in a wild-type background. For the construction of the integrating nmt1-GST-chk1 fusion vector (pBF161), the PstI-SstI fragment from pBF147 was ligated into the PstI and SstI sites of pIK148 (Keeney and Boeke 1994). Integration was targeted to the leu1-32 locus in OMI603.

\section{Acknowledgments}

We thank Kathleen Gould for the $\alpha$-Cdc13 antibody and the $c d c 2-Y 15 F$ strain, Steve Reed for the $\alpha$-PSTAIR antibody, Tony Carr for the nmt1-chk1 fusion, and members of the Russell laboratory for advice and comments. This work was supported by a National Institutes of Health grant awarded to P.R.

The publication costs of this article were defrayed in part by payment of page charges. This article must therefore be hereby marked "advertisement" in accordance with 18 USC section 1734 solely to indicate this fact.

\section{References}

al-Khodairy, F. and A.M. Carr. 1992. DNA repair mutants defining G2 checkpoint pathways in Schizosaccharomyces pombe. ЕМBO I. 11: 1343-1350.
al-Khodairy, F., E. Fotou, K.S. Sheldrick, D.J. Griffiths, A.R. Lehmann, and A.M. Carr. 1994. Identification and characterization of new elements involved in checkpoint and feedback controls in fission yeast. Mol. Biol. Cell 5: 147-160.

Aligue, R., N.H. Akhavan, and P. Russell. 1994. A role for Hsp90 in cell cycle control: Weel tyrosine kinase activity requires interaction with Hsp90. EMBO J. 13: 6099-6106.

Amon, A., U. Surana, I. Muroff, and K. Nasmyth. 1992. Regulation of $\mathrm{p} 34^{\mathrm{CDC} 28}$ tyrosine phosphorylation is not required for entry into mitosis in S. cerevisiae. Nature 355: 368-371.

Barbet, N.C. and A.M. Carr. 1993. Fission yeast Weel protein kinase is not required for DNA damage-dependent mitotic arrest. Nature 364: 824-827.

Brizuela, L., G. Draetta, and D. Beach. 1987. p13 ${ }^{\text {suc } 1}$ acts in the fission yeast cell division cycle as a component of the p34 $4^{\text {cdc2 }}$ protein kinase. EMBO J. 6: 3507-3514.

Carr, A.M. 1995. DNA structure checkpoints in fission yeast. Semin. Cell Biol. 6: 65-72.

Creanor, J. and J.M. Mitchison. 1979. Reduction of peturbations in leucine incorporation in synchronous cultures of Schizosaccharomyces pombe. I. Gen. Microbiol. 112: 385-388.

Dunphy, W.G. 1994. The decision to enter mitosis. Trends Cell Biol. 4: 202-207.

Enoch, T. and P. Nurse. 1990. Mutation of fission yeast cell cycle control genes abolishes dependence of mitosis on DNA replication. Cell 60: 665-673.

Featherstone, C. and P. Russell. 1991. Fission yeast p107 ${ }^{\text {weel }}$ mitotic inhibitor is a tyrosine/serine kinase. Nature 349: $808-811$.

Ford, J.C., F. al-Khodairy, E. Fotou, K.S. Sheldrick, D.J. Griffiths, and A.M. Carr. 1994. 14-3-3 protein homologs required for the DNA damage checkpoint in fission yeast. Science 265: 533-535.

Fry, A.M. and E.A. Nigg. 1995. Cell cycle. The NIMA kinase joins forces with Cdc2. Curr. Biol. 5: 1122-1125.

Gould, K.L. and P. Nurse. 1989. Tyrosine phosphorylation of the fission yeast $c d c 2^{+}$protein kinase regulates entry into mitosis. Nature 342: 39-45.

Gould, K.L., S. Moreno, D.J. Owen, S. Sazer, and P. Nurse. 1991. Phosphorylation at Thr167 is required for Schizosaccharomyces pombe p34 ${ }^{\mathrm{cdc} 2}$ function. $E M B O /$. 10: 3297-3309.

Harlow, E. and D. Lane. 1988. Antibodies: A laboratory manual. Cold Spring Harbor Laboratory, Cold Spring Harbor, NY.

Hartwell, L.H. and M.B. Kastan. 1994. Cell cycle control and cancer. Science 266: 1821-1828.

Herzinger, T., J.O. Funk, K. Hillmer, D. Eick, D.A. Wolf, and P. Kind. 1995. Ultraviolet B irradiation-induced G2 cell cycle arrest in human keratinocytes by inhibitory phosphorylation of the cdc2 cell cycle kinase. Oncogene 11: 2151-2156.

Jin, P., Y. Gu, and D.O. Morgan. 1996. Role of inhibitory CDC2 phosphorylation in radiation-induced G2 arrest in human cells. J. Cell Biol. 134: 963-970.

Keeney, J.B. and J.D. Boeke. 1994. Efficient targeted integration at leu1-32 and ura4-294 in Schizosaccharomyces pombe. Genetics 136: 849-856.

Kovelman, R. and P. Russell. 1996. Stockpiling of Cdc25 during a DNA replication checkpoint arrest in Schizosaccharomyces pombe. Mol. Cell. Biol. 16: 86-93.

Krek, W. and E.A. Nigg. 1991. Mutations of $\mathrm{p} 34^{\mathrm{cdc} 2}$ phosphorylation sites induce premature mitotic events in HeLa cells: Evidence for double block to p34 $4^{\mathrm{cdc} 2}$ kinase activation in vertebrates. $E M B O$ \%. 10: 3331-3341.

Kumagai, A. and W.G. Dunphy. 1996. Purification and molecular cloning of Plxl, a Cdc25-regulatory kinase from Xenopus egg extracts. Science 273: 1377-1380. 
Lee, M.S., T. Enoch, and H. Piwnica-Worms. 1994. mik1 ${ }^{+}$encodes a tyrosine kinase that phosphorylates p34 $4^{\text {cdc2 }}$ on tyrosine 15. T. Biol. Chem. 269: 30530-30537.

$\mathrm{Lu}$, K.P. and T. Hunter. 1995. Evidence for a NIMA-like mitotic pathway in vertebrate cells. Cell 81: 413-424.

Lundgren, K., N. Walworth, R. Booher, M. Dembski, M. Kirschner, and D. Beach. 1991. mik1 and wee1 cooperate in the inhibitory tyrosine phosphorylation of $c d c 2$. Cell 64: $1111-$ 1122.

Maundrell, K. 1990. nmt1 of fission yeast. A highly transcribed gene completely repressed by thiamine. I. Biol. Chem. 265: 10857-10864.

1993. Thiamine-repressible expression vectors pREP and $\mathrm{pRIP}$ for fission yeast. Gene 123: 127-130.

McGowan, C.H. and P. Russell. 1993. Human Weel kinase inhibits cell division by phosphorylating p34 ${ }^{\text {cdc2 }}$ on Tyr15. EMBO I. 12: 75-85.

Millar, J.B.A., C.H. McGowan, G. Lenaers, R. Jones, and P. Russell. 1991. p80 ${ }^{\mathrm{cdc} 25}$ mitotic inducer is the tyrosine phosphates that activates $\mathrm{G}_{2}$-phase $\mathrm{p} 34^{\mathrm{cdc} 2}$ kinase in fission yeast. EMBO J. 10: 4301-4309.

Millar, J.B.A., G. Lenaers, and P. Russell. 1992. pyp3 PTPase acts as a mitotic inducer in fission yeast. $E M B O T$. 11: 49334941.

Moreno, S., I. Hayles, and P. Nurse. 1989. Regulation of $\mathrm{p} 34^{\mathrm{cdc} 2}$ protein kinase during mitosis. Cell 58: 361-372.

Moreno, S., A. Klar, and P. Nurse. 1991. Molecular genetic analysis of fission yeast Schizosaccharomyces pombe. Methods Enzymol. 194: 795-723.

Norbury, C., J. Blow, and P. Nurse. 1991. Regulatory phosphorylation of the $\mathrm{p} 34^{\mathrm{cdc} 2}$ protein kinase in vertebrates. EMBO $\%$. 10: 3321-3329.

Nurse, P. 1990. Universal control mechanism regulating onset of M-phase.Nature 344: 503-508.

O'Connor, P.M., D.K. Ferris, I. Hoffmann, J. Jackman, G. Draetta, and K.W. Kohn. 1994. Role of the cdc25 phosphatase in G2 arrest induced by nitrogen mustard. Proc. Natl. Acad. Sci. 91: 9480-9484.

Parker, L.L., S. Atherton-Fessler, and H. Piwnica-Worms. 1992. $\mathrm{p} 107^{\text {weel }}$ is a dual-specificity kinase that phosphorylates p34 ${ }^{\mathrm{cdc} 2}$ on tyrosine 15. Proc. Nat1. Acad. Sci. 89: 2917-2921.

Russell, P. and P. Nurse. 1986. $c d c 25^{+}$functions as an inducer in the mitotic control of fission yeast. Cell 45: 145-153.

. 1987. Negative regulation of mitosis by wee $1^{+}$, a gene encoding a protein kinase homolog. Cell 49: 559-567.

Sheldrick, K.S. and A.M. Carr. 1993. Feedback controls and G2 checkpoints: Fission yeast as a model system. Bioessays 15: $775-782$.

Sorger, P.K. and A.W. Murray. 1992. S-phase feedback control in budding yeast independent of tyrosine phosphorylation of $\mathrm{p} 34^{\mathrm{cdc} 28}$. Nature 355: 365-368.

Walworth, N.C. and R. Bernards. 1996, rad-dependent response of the chk1-encoded protein kinase at the DNA damage checkpoint. Science 271: 353-356.

Walworth, N., S. Davey, and D. Beach. 1993. Fission yeast Chk1 protein kinase links the rad checkpoint pathway to $\mathrm{Cdc} 2$. Nature 363: 368-371.

Weinert, T.A. and L.H. Hartwell. 1988. The RAD9 gene contols the cell cycle response to DNA damage in Saccharomyces cerevisiae. Science 241: 317-322. 


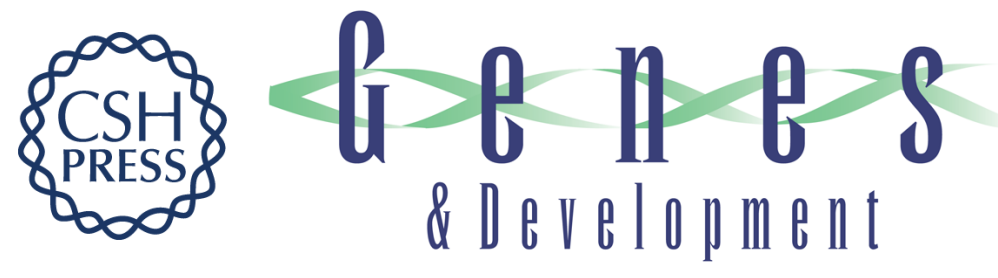

\section{Cdc2 tyrosine phosphorylation is required for the DNA damage checkpoint in fission yeast.}

N Rhind, B Furnari and P Russell

Genes Dev. 1997, 11:

Access the most recent version at doi:10.1101/gad.11.4.504

References This article cites 43 articles, 12 of which can be accessed free at: http://genesdev.cshlp.org/content/11/4/504.full.html\#ref-list-1

License

Email Alerting

Service

Receive free email alerts when new articles cite this article - sign up in the box at the top right corner of the article or click here.

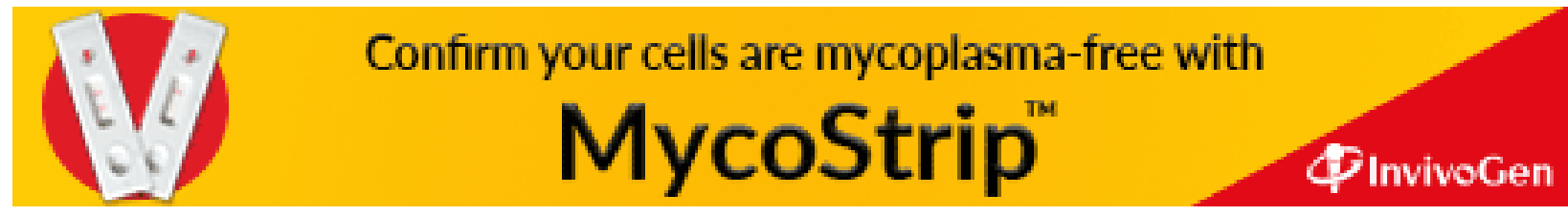

